\title{
Active Power Decoupling Topology for Single Phase Bridge Inverter based on Buck-Boost Convertor
}

\author{
Manoj Hans, Kiran Godashe, Satya Prakash, Anamika Chourasia
}

\begin{abstract}
Increasing demand of power has led to exploration of non-conventional sources of energy. Solar energy has been the most exploited source of energy in this regard. Effectiveness of power utilization depends on the power conversion from AC to DC. Further improvement in utilization of DC power depends on the DC-DC conversion steps involved. The planned methodology offers a study of power decoupling method while no further power semiconductor are used for a DC to 1- $\phi$ AC device. 1- $\phi$ voltage source bridge inverters have primarily two drawbacks, that's reduction in DC voltage usage and disparity in power among the incoming and outgoing sides. These difficulties have been looked upon and a topology has been implemented that uses just a film capacitance beforehand buck-boost convertor that is linked to the voltage-source bridge inverter. Reenactment and preliminary outcome confirmed the credibility of the planned power decoupling technique on the 2-stage 1-\$ bridge inverter by buck-boost convertor.
\end{abstract}

Keywords: 1- $\phi$ AC convertor, Buck-boost convertor, voltage-source bridge inverter

\section{INTRODUCTION}

Renewable energy production has developed a demand in recent years. Recently, several energy consultants, experts, engineers and campaigners have aggressively promoted this vision. Consistent with recent information, we have consumed nearly $2 / 3$ of carbon reserves and also the present estimate indexes the complete reserve is going to be utilized till 2050. Therefore, it's vital to maneuver quickly to renewable energy. Solar electrical phenomenon (PV) generation is turning into progressively vital as a renewable energy supply, because it has several benefits, through the PV cell, however desires DC-to-AC converters with adequate reverse amplification circuits. The projected system implies to the buck-boost convertor and also the inverter of the

Revised Manuscript Received on December 30, 2019.

* Correspondence Author

Manoj Hans, Department of Electrical Engineering, Zeal College of Engineering \& Research, Pune, India.

Kiran Godashe, Department of electrical Engineering, Rajaram Shinde college of Engineering, Chiplun, India.

Satya Prakash*, Department of Electrical Engineering, Zeal College of Engineering \& Research, Pune, India.

Anamika Chourasia, Department of Electrical Engineering, Govt. Polytechnic College, Naogaon, India,

(C) The Authors. Published by Blue Eyes Intelligence Engineering and Sciences Publication (BEIESP). This is an open access article under the CC BY-NC-ND license (http://creativecommons.org/licenses/by-nc-nd/4.0/) sinusoidal voltage supply may be applicable to the PV grid system. A 1- $\phi$ voltage supply bridge inverters are usually employed in renewable energy systems like electrical phenomenon (PV) systems to alter DC into AC. However, the electric circuit has solely restrictions like a minimum use of DC on the shortage of regulation of the power of the 2 nd-order.The 2-step 1- $\phi$ inverter by a booster convertor or forward pulse convertor at the front will increase the DC input voltage higher than the AC peak and also the next stage of the bridge provides power for the AC part. As the DC incoming side voltage is far more than AC amplitude, the buck convertor will scale back the DC voltage for the purpose of the modulation range of succeeding bridge step is truly used. In each case, a big size capacitor is required for decoupling of passive power for the reason that of the misalliance of the frequency power of the double line among the DC as well as AC aspect and also the electrolytic capacitance has large dimensions and a brief period solely a minor portion of the probable helpful generation of photovoltaic systems. An analysis of $1-\phi$ bridge inverter or electrical convertor with decoupled active voltage reference power supported a buck-boost convertor has been discussed.

\section{LITERATURE SURVEY}

So far, several ways are planned to enhance reliability and, within the meanwhile, to attain a maximum energy density, to create the matter of power decoupling troublesome. To deal with these issues, new approaches to decoupling active power for single-phase systems are explored. Authors have given a way for decoupling the power supply while not extra power electronic elements, planned for a single-phase DC to AC convertor, that solely adds a tiny low foil capacitance to the input side Buck-boost convertor and bridge inverter with voltage supply [1],[2]. Authors have thrown light on the outline of all the planned techniques till the presentation of this add order to scale back the power fluctuation in 1- $\phi$ applications. Given pulsing energy is that the main issue to extend the passive parts and also the losses within the inverter and might be accountable for losses or malfunctions of the DC supply [3]. Entire summary of the topologies of decoupling circuits of active power has been discussed. They're divided into two teams in relationships of property of the assembly: topologies of freelance and in need of decoupling circuits. The primary works alone with the first convertor and also the second half, however, partly and even utterly bonds the semiconductor devices conjointly with the first convertor [4],[5]. 
Authors have presented a replacement micro inverter methodology for 1- $\phi$ photovoltaic systems linked to the grid. Also propose a topology ready to remove dispersion current in a very common method, sitting an excellent challenge in PV inverters while not transformers. A new circuit arrangement associated with control theme for a $1-\phi$ inverter has been discussed [6-8]. A brand-new methodology for decoupling real power employing a 6-switch 1- $\phi$ inverter methodology has been proposed. A tiny low film capacitor is employed as a pulsing energy damper on the AC side, that not solely advances dependability however conjointly efficiency [9]. A methodology has been proposed for a (PWM) rectifier that may get each the sine wave current on the AC section as decoupling of the ripple on the DC section while not using extra switches [10],[11]. Authors have mentioned a fresh technique of configuring and controlling the circuit for power factor improvement of a 1- $\phi$ convertor from AC to DC and a decoupling function of power pulse [12],[13]. Authors have presented a technique decoupling of power supported a 3-port DC / DC / AC convertor and 4 DC switches of micro-network. The planned methodology has 3 boundaries that may be linked to DC power, to the capacitance and to the AC power source [14][15]. Authors have discussed the configuration for a 1- $\phi$ voltage inverter while decoupling the power supply. It's sometimes necessary for the electrical converter linked to a 1- $\phi$ network to show off the power wave at doubly the line frequency [16], [17].

\section{PROPOSED METHODOLOGY}

The authors have projected a fresh decoupling topology for active power. A 3rd limb, an energy storing capacitance and a leveling inductor is included in the circuit. This scheme combines the benefits of maximum energy storage potency and bandwidth of small control requirements. The paper give a comprehensive summary of the event of $1-\phi$ power convertor methodologies that support decoupling techniques. The benefits and drawbacks of every topology were conferred and compared with those of its predecessors, highlight the essential logic within the development of topologies. Authors have discussed a convertor that demonstrate nonstop conductivity manner likewise as reduced turn off switching losses as a result of switching topology that uses Lr-Cr resonance within the secondary circuit. Paper describes the reduction strategies for the energy loading/storing capacitance for the $1-\phi$ rectifier and connectivity of same with the grid has been discussed.

\section{A. Traditional 1- $\phi$ Bridge type Inverter with Big Size Capacitor:}

In this topology the conventional technique has been analysed for a reference in order to implement the improvements. In the figure 1 the methodologies of the traditional 1- $\phi$ bridge inverter using boost convertor or step-up convertor is displayed. The pulsating power elements on the DC input, on the intermediate circuit and on the AC output of the traditional inverter are displayed in Figure 2. Maximum of the 2nd-order pulsating power element should be soaked by the middle circuit capacitance; however, the middle circuit capacitance has similar oscillation percentage of voltage as the DC input. In order to decrease the power pulse from the DC incoming supply, it is necessary to put a big size electrolytic capacitor Ce on the DC input or the DC link to reduce voltage oscillations and soaking of the pulsating power (ripple).

Considering that the planning constraint for the oscillation of the incoming DC voltage has to be smaller than \pm 2 which the 2nd-order pulsating power provided through the DC supply (photovoltaic module or batteries) is a smaller amount than $5 \%$. The variation of the intermediate circuit voltage should even be smaller amount than \pm 2 and therefore the residual $95 \%$ of the pulsating power is provided to the intermediate circuit capacitance Ce. Therefore, it's attainable to calculate the minimum capacity of the middle circuit.

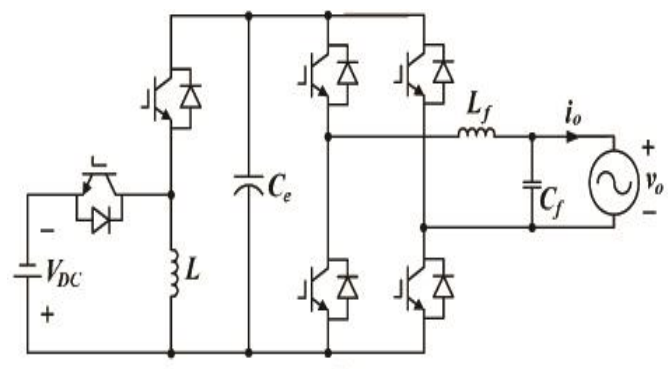

(a)

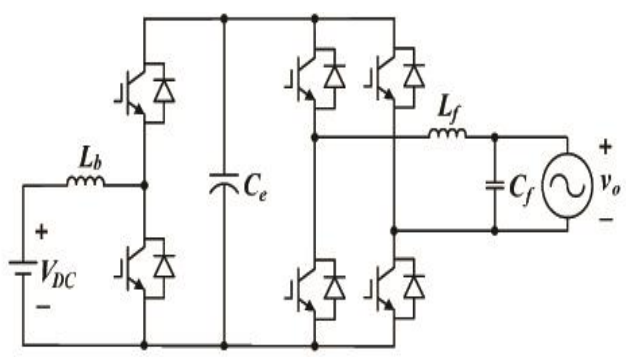

(b)

Fig.1. 1- $\phi$ bridge type inverter with: (a) buck-boost convertor; (b) boost convertor.

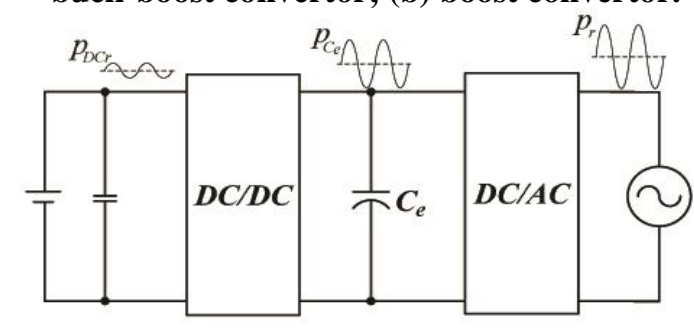

Fig. 2. 2-stage 1- $\phi$ bridge inverter

\section{B. 1- $\phi$ Bridge Inverter with Decoupling Capacitor}

The overview discusses few circuits of active power decoupling attached to traditional methodologies to send 2nd- order ripple power from the foremost power way to capacitors of small thin film, however the extra power electronics have raised prices as well as power loss. To take care of this problem, in Fig. 4 a projected $1-\phi$ bridge inverter through active power decoupling built on the buck- boost converter is given that adds solely a small thin film decoupling capacitance to the start-end buck-boost convertor. With corresponding triggering signals, if the buck-boost convertor is functioned, then the current of the inductor is often constant and therefore the relationship among the voltage of the DC-link $v_{\text {link }}$ and therefore the voltage of the input side DC that is $V_{d c}$ given by: 


$$
v_{\text {link }}=\frac{d_{c}}{1-d_{c}} \cdot V_{d e}
$$

Here, $d_{c}$ is corresponds to switch $S_{c_{1}}$ duty cycle and therefore in Figure 3 polarities are given.

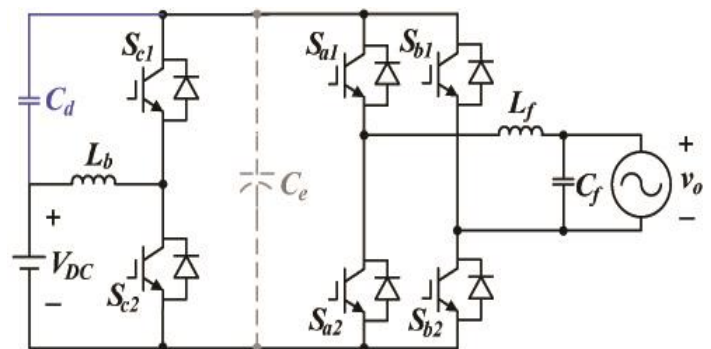

Fig. 3. Bridge inverter built on buck-boost convertor.

Then the voltage of capacitor $C_{\mathbb{d}}$ that is $v_{C_{d}}$ is given by:

$$
v_{C_{d}}=V_{d e}+v_{\text {link }}=\frac{1}{1-d_{c}} V_{d e}
$$

Thus, the voltage of the capacitor $C_{d}$ will be measured as a double frequency polarized DC wave and therefore DC offset is employed to manage the voltage of intermediate circuit rather than unused as within the methodologies specified above.

\section{Active Power Decoupling Principle}

Conferring to the compensation principle of the ripple power given in Figure 4, the pulsating power element of the scheme is more examined. Considering AC input the voltage $v_{0}$, the current $i_{0}$, the instant power $p_{0}$ and assuming the system is functioning at power factor unity, i.e. $\cos \varphi=1$, the current flowing through the $C_{f}$ may be written as:

$$
i_{C_{f}}=C_{f} \cdot \frac{d v_{n}}{d t}=I_{C_{f}} \cdot \cos (\omega t)
$$

Therefore $v_{0}=v_{\text {grid }}$ is that the voltage of AC load, $I_{C_{f}}=\omega C_{f} V_{0}$ is that the max current of filter capacitance. At that moment, the instantaneous power soaked through the $C_{f}$ will be:

$$
P_{C_{F}}=v_{0} i_{C_{F}}=V_{0} I_{C_{F}} \cdot \sin (2 \omega t)
$$

After this it will be seen that the 2nd-order pulsating power derives from each the AC load and also the filter capacitance. To send the 2nd -order pulsating power to the decoupling capacitance $C_{d}$, the film capacitance voltage ${ }^{V_{C d}}$ ought to be controlled in a way that the instantaneous power ${ }^{P} C_{\text {II }}$ soaked by film capacitor $C_{d}$ will be:

$$
p_{C_{d}}=P_{0} \cdot \cos (2 \omega t+\varphi)-P_{C_{f}} \cdot \sin (2 \omega t)
$$

Where $P_{0}=V_{0} I_{0} \& P_{C_{f}}=V_{0} I_{C_{f}}$

Conferring to equation (3), the voltage of the decoupling capacitance $v_{C_{d I}}$ is often bigger than the incoming side DC voltage $V_{d e}$. To soak up the 2nd-order ripple power, the voltage of decoupling capacitance $V_{d e}$ is actually a DC polarized wave that oscillates at a dual line frequency just like the green wave shape in Figure 4 which has a DC shift $V_{d}$ may be a 2nd-order element $V_{C_{A C}}{ } \sin (2 \omega t+\theta)$. Therefore, the power, energy and voltage equations for the capacitor $C_{d}$ are stated as follows:

$$
v_{C d}(t)=V_{d}+V_{C_{A L}} \cdot \sin (2 \omega t+\theta)
$$

$$
\begin{aligned}
& E_{C d}(t)=\frac{1}{2} C_{d} V_{d}^{2}+C_{d} V_{d} V_{C_{A E}} \sin (2 \omega t+\theta)+ \\
& \frac{1}{4} C_{d} V_{C_{A E}}{ }^{2}(1-\cos (4 \omega t+2 \theta)) \\
& p_{C d}(t)=2 \omega C_{d} V_{d} V_{C_{A E}} \cdot \cos (2 \omega t+\theta)+\omega C_{d} V_{C_{A E}}{ }^{2 .} \\
& \sin (4 \omega t+2 \theta)
\end{aligned}
$$

The ripple element for the 2nd-order of $P_{c d}(t)$ are often utilized to delete the 2nd-order ripple element on the AC side, however at identical time a 4th-order ripple element is additionally introduced, as revealed in (9). To eliminate the 4th-order ripple element, the decoupling capacitance voltage is taken as:

$$
v_{C d}=V_{d}+v_{C_{A C}} v_{C d}=V_{d}+v_{C_{A E}}
$$

Where ${ }^{V_{C A E}}$ is that the AC element of ${ }^{V_{C d}}$ and might contain totally different harmonics rather than a straightforward 2nd-order. The extra AC element ${ }^{{ }^{V_{C}}}{ }_{C_{E}}$ is calculated as:

$$
\begin{aligned}
& v_{C_{A E}}=-V_{d}+ \\
& \sqrt{V_{d}{ }^{2}+\frac{V_{D} I_{Q}}{\omega C_{d I}} \cdot \sin (2 \omega t+\varphi)+\frac{C_{f}}{C_{d I}} V_{0}{ }^{2} \cdot \cos (2 \omega t)}
\end{aligned}
$$

Therefore, the decoupling capacitor's reference voltage is considered as:

$v_{C d}{ }^{*}=\sqrt{V_{d}^{2}+\frac{V_{0} I_{Q}}{\omega C_{d}} \cdot \sin (2 \omega t+\varphi)+\frac{C_{f}}{C_{d I}} V_{0}^{2} \cdot \cos (2 \omega t)}$

It may be seen that the voltage of the decoupling capacitance is that the root of a 2nd order DC polarized harmonic and not simply polarized DC wave that varies double the amplitude and therefore the frequency of the voltage is reciprocally proportional to the decoupling capacitance $C_{d}$. In different words, the decoupling capacitance comprises a maximum voltage variation with reduced capability and maybe mentioned in additional detail within the next segment for element construction. The forward-facing boost convertor duty cycle $d_{C}{ }^{*}$ taken as reference may be written as:

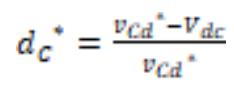

The peak 2nd-order ripple power corresponds to the DC power $P_{D C}$ utilizing the unity power factor. To fully eliminate the 2nd-order ripple, the decoupling capability should be planned as follows:

$$
C_{d}=\frac{P_{b E}}{2 w V_{d} V_{\mathbb{L}_{A C}}}
$$

Where $P_{D C}$ corresponds to average DC power, indicates the DC counterpoise or the average voltage of capacitance and is the entity of the fluctuation of the capacitance voltage. 
At mounted power, the capability of decoupling is reciprocally proportional to compensation of the DC and therefore the capacitance swell voltage. Figure 4 shows the connection between oscillation of the decoupling capacitance voltage and therefore the decoupling capability below the nominal power of $400 \mathrm{~W}$. With a DC incoming side voltage of $100 \mathrm{~V}$ and an output side voltage of $110 \mathrm{rms}$, the middle circuit voltage is about $220 \mathrm{~V}$. Therefore, the DC compensation for the inverter topology decoupling capacitance in Figure 4 is ready to $120 \mathrm{~V}$, whereas the topology projected in Figure 4 ought to be set to 320 V. So, it's shown in Figure 5 that the capacitance decoupling capacitor within the projected method encompasses a lot of lower capability as compared to decoupling capacitance in Figure 5 with a similar voltage fluctuation.

The inductance of buck-boost is employed for power handover among the DC supply and the load at the output. Within the stable state, the charging of energy in buck-boost inductor is dissipated nearly either in capacitor or to the load throughout every switching cycle. The inductor current wave is constant as well as bipolar because of the two-way process. The ripple in the current $\Delta \mathrm{I}$ is obtained as follows:

$$
\Delta I=\frac{V_{D E}}{L} d_{c} T_{s}
$$

In this case, the switching duration and also the inversely proportional of the switching frequency f_s, that is $10 \mathrm{kHz}$. The inductance is meant in such way that $\Delta \mathrm{I}$ is a smaller amount than 30 A to sidestep saturation of the inductance and peak voltage. Figure 4 shows the link between the ripple of the inductor current and also the increase in inductance with a distinct rate of increase of the investment. The inductance is reciprocally proportional to the ripple of current of the inductor and additionally the ratio of buck-boost is of minor importance for the slightest inductance of buck-boost once there is high ripple.

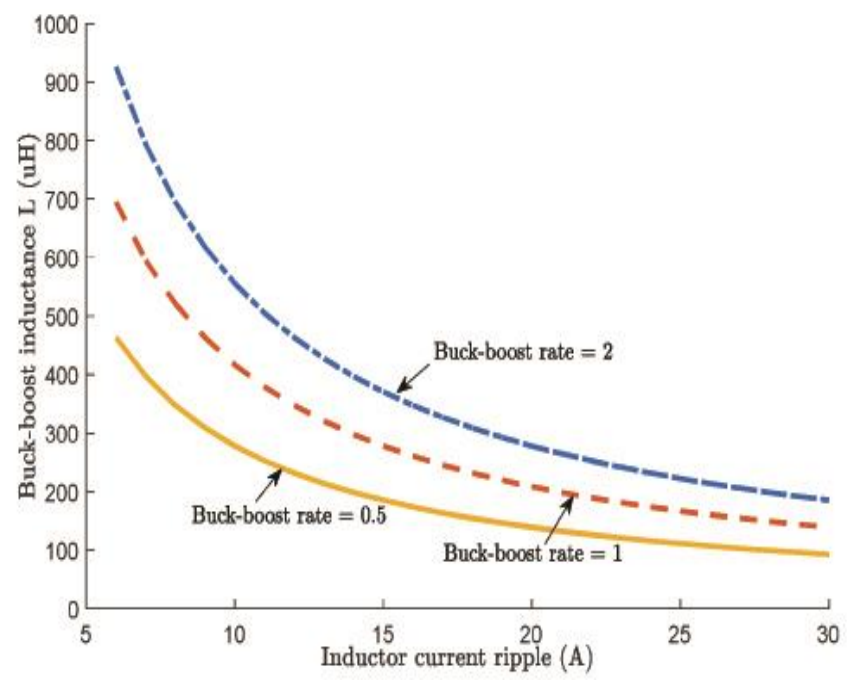

Fig. 4. Relationship among voltage of oscillating capacitor and decoupling capacitance.

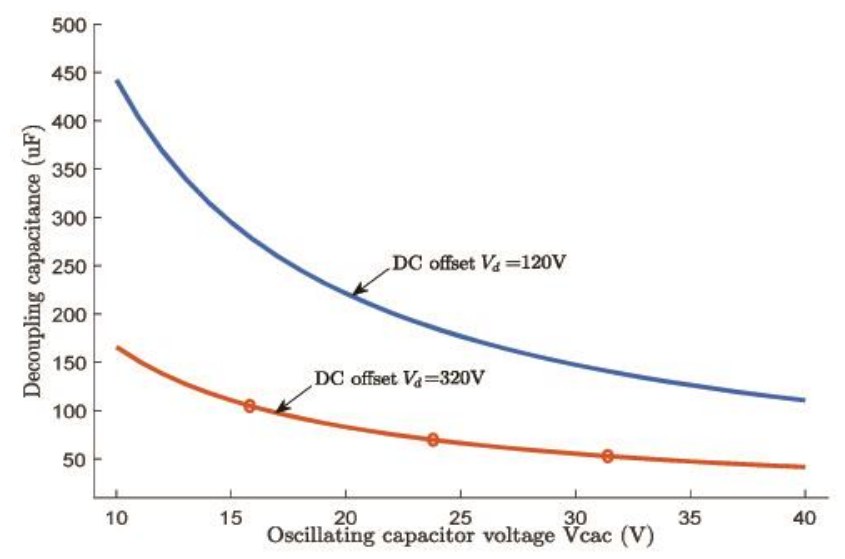

Fig. 5. Relationship among current ripple in the inductor and inductance of the buck-boost.

\section{HARDWARE IMPLEMENTATION}

The below figure shows the experimental setup of the proposed single-phase bridge inverter with power decoupling based on buck-boost converter.
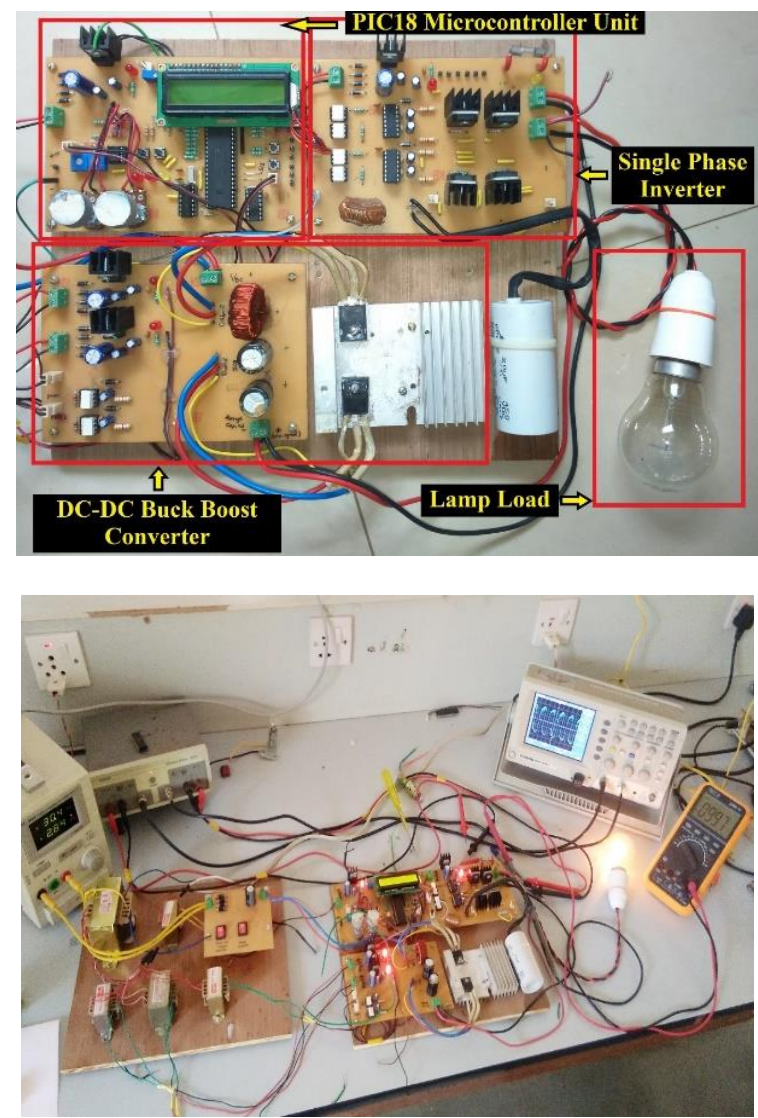

Fig. 6. Hardware of the projected 1- $\phi$ bridge inverter.

\section{RESULTS \& DISCUSSION}

The MATLAB simulation software package is employed to simulate the 1- $\phi$ bridge inverter by active power decoupling supported the buck-boost converter. In an inverter arrangement with electric battery supply with a DC incoming side voltage of $30 \mathrm{~V}$, the resistive load at the output incorporates a maximum AC output side voltage of $100 \mathrm{~V}$. The foremost vital parameters are listed in Table 1 . The outcomes of the simulation are given in Figure 7.

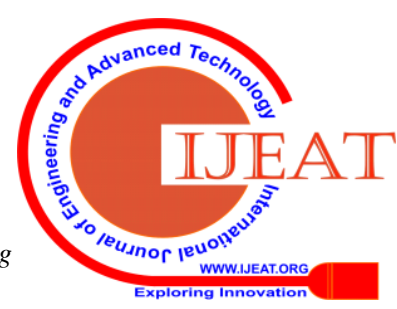



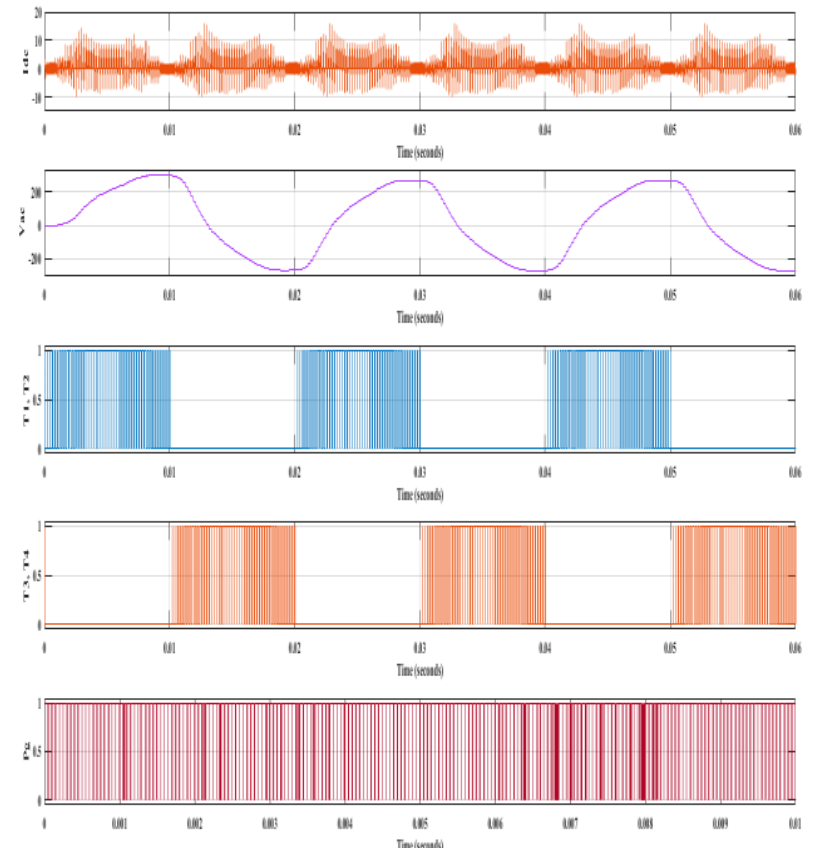

Fig. 7. Simulation outcomes of the projected 1- $\phi$ bridge inverter: showing incoming side DC current IDC, output side AC voltage Vac, with respective SPWM pulses.

Figure 6 show the hardware of the projected 1- $\phi$ bridge inverter. Figure 8 (a) - (d) show the wave shapes of the incoming DC current, the AC output side voltage and likewise the SPWM pulse of IGBT1 and IGBT2 with reference to the AC output side voltage. The DC input voltage is about to $30 \mathrm{~V}$ and also the inverter functions at nominal rated power. In Figure 8 (a), the fluctuation of the DC input current is with success corrected. The AC output voltage may be a pure sinusoidal wave with a peak of roughly 100 V. Figure 8 (b) shows the SPWM pulses sent to the 1- $\phi$ bridge inverter. The DC input side current is about $3 \mathrm{~A}$ and also the 2nd-order element has nearly been removed.

Table -1: Observed values after simulation

\begin{tabular}{|c|l|c|}
\hline Sr.No. & \multicolumn{1}{|c|}{ Parameter } & Rating \\
\hline $\mathbf{1}$ & Incoming DC Voltage Vdc & $30 \mathrm{~V}$ \\
\hline $\mathbf{2}$ & Max Output side AC Voltage $\mathrm{V}_{0}$ & $100 \mathrm{~V}$ \\
\hline $\mathbf{3}$ & Filtering Inductance $\mathrm{L}_{\mathrm{f}}$ & $0.8 \mathrm{mH}$ \\
\hline $\mathbf{4}$ & Fly-back Inductance $\mathrm{L}$ & $1.8 \mathrm{mH}$ \\
\hline $\mathbf{5}$ & Filtering Capacitance $\mathrm{C}_{\mathrm{f}}$ & $20 \mu \mathrm{H}$ \\
\hline $\mathbf{6}$ & Power Decoupling Capacitance Cd & $47 \mu \mathrm{H}$ \\
\hline $\mathbf{7}$ & AC Frequency $\mathrm{f}_{\mathrm{AC}}$ & $50 \mathrm{~Hz}$ \\
\hline $\mathbf{8}$ & Frequency of Inverter & $10 \mathrm{KHz}$ \\
\hline $\mathbf{9}$ & $\begin{array}{l}\text { Switching frequency of Buck-Boost } \\
\text { Convertor }\end{array}$ & $100 \mathrm{KHz}$ \\
\hline
\end{tabular}

A laboratory model was created with a PIC18F4520 microcontroller to supply safety and control meanings for the inverter. Primary experimental outcomes are shown in Figure 8 , which has the wave shapes of the DC, AC and SPWM pulses coming into the IGBT to make sure that the bridge inverter ne'er grasps the over modulation range. In Figure 8 (a), the 2nd-order ripple within the DC incoming side current was eliminated, indicating the proper decoupling of the power supply.

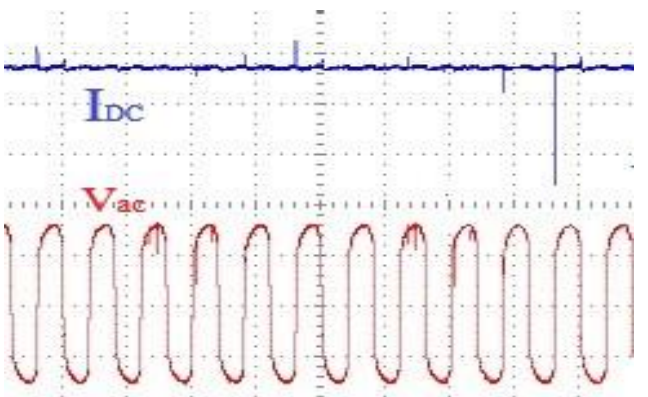

(a)

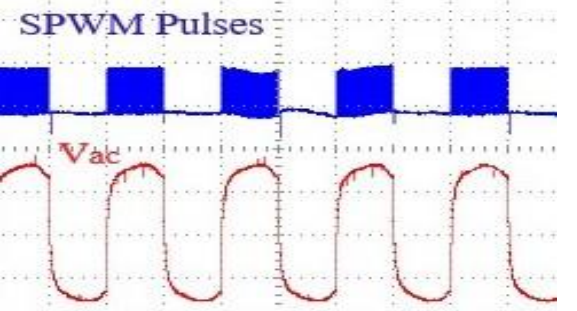

(b)

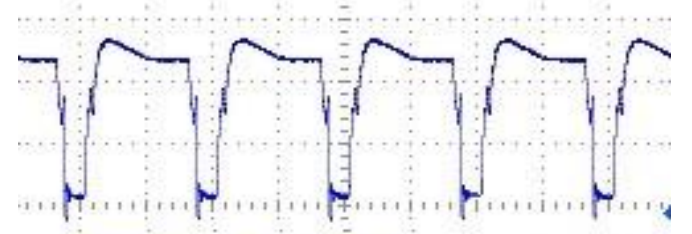

\section{IGBT1 Gate Pulse}

(c)

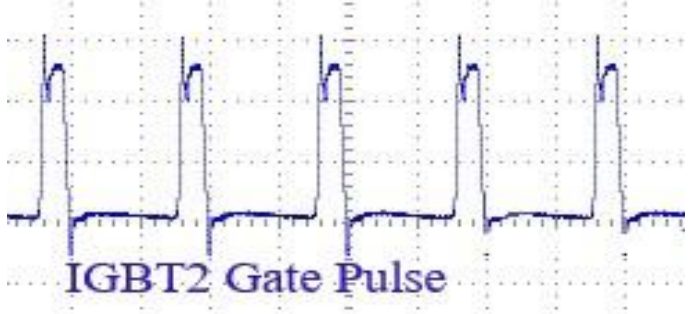

(d)

Fig. 8. Experimental outcomes of the projected 1- $\phi$ bridge inverter: (a) Incoming DC current with output side AC Voltage (b) SPWM Pulses with respect to output voltage (c) Gate Pulse for IGBT1 of Buck-Boost converter (d) Gate Pulse for IGBT2 of Buck-Boost converter

\section{CONCLUSION}

Considering the modifications made in the system, it was noticed that the proposed model do have desired output. The required DC output was available as per the requirement. This topology uses a brand-new power decoupling method during which it's attainable to use a tiny low film capacitor rather than the electrolytic. Therefore, it'll take an extended life similar to the electrical phenomenon like PV panel. MATLAB and investigational outcomes show that the 1- $\phi$ bridge inverter attains a booming decoupling of the power supply by a major decrease of the 2nd-order DC element with a decent load capability. 


\section{REFERENCES}

1. Xu, Shuang, Liuchen Chang, Riming Shao, and AR Haider Mohomad. "Single-Phase Bridge Inverter with Active Power Decoupling Based on Buck-Boost Converter." IEEE Energy Conversion Congress and Exposition (ECCE), pp. 6725-6732. IEEE, 2018.

2. Vitorino, Montie Alves, Luciano Francisco Sousa Alves, Ruxi Wang, and Maurício Beltrão de Rossiter Corrêa. "Low-frequency power decoupling in single-phase applications: A comprehensive overview." IEEE Transactions on Power Electronics 32, no. 4 (2016): 2892-2912.

3. Sun, Yao, Yonglu Liu, Mei Su, Wenjing Xiong, and Jian Yang. "Review of active power decoupling topologies in single-phase systems." IEEE Transactions on Power Electronics, 31, no. 7 (2015): 4778-4794.

4. M. Rama Subbamma, V. Madhusudhan,P. Sujatha "Design and Analysis of $4 \mathrm{Kw}$ Srm Drive for Air-Conditioned Pwm Rectifier and Buck-Boost Pfc Converter", IJEAT, Volume. 9, Issue 1, 1344-1352, 2019.

5. S. Harb, H. Hu, N. Kutkut, I. Batarseh and Z. J. Shen, "A three-port photovoltaic (PV) micro-inverter with power decoupling capability," in Proc. 26th Annual IEEE Applied Power Electronics Conference Exposition (APEC), March 2011, pp. 203-208.

6. Y. Xia, J. Roy and R. Ayyanar, "A GaN based doubly grounded, reduced capacitance transformer-less split phase photovoltaic inverter with active power decoupling," IEEE Applied Power Electronics Conference and Exposition (APEC), Tampa, FL, USA, 2017, pp. 2983-2988.

7. Hüseyin ÇALIK,S. Hakan UNDİL,Hasan Hüseyin ÇELİK "C-Dump Converter Design and its Dynamic Analysis in Simulink Environment for a Switch Reluctance Machine" IJEAT, Volume. 9, Issue 1, 5144-5148, 2019.

8. Y. Ohnuma, K. Orikawa and J. Itoh, "A single-phase current-source PV inverter with power decoupling capability using an active buffer," IEEE Transaction Industrial Application, vol. 51, no. 1, pp. 531-538, Jan. 2015.

9. S. Fan, Y. Xue and K. Zhang, "A novel active power decoupling method for single-phase photovoltaic or energy storage applications," in Proc. IEEE Energy Conversion. Congress and Exposition (ECCE), Sept. 2012, pp. 2439-2446.

10. W. Qi, H. Wang, X. Tan, G. Wang and K. D. Ngo, "A novel active power decoupling single-phase PWM rectifier topology," in Proc. 29th Annual IEEE Application Power Electronics Conference Exposition (APEC), March 2014, pp. 89- 95.

11. Y. Ohnuma and J. Itoh, "A novel single-phase buck PFC AC-DC converter with power decoupling capability using an active buffer," IEEE Transition Industrial Application, vol. 50, no. 3, pp. 1905-1914, May 2014.

12. W. Cai, L. Jiang, B. Liu, S. Duan and C. Zou, "A power decoupling method based on four-switch three-port DC/DC/AC converter in DC Microgrid," IEEE Transaction Industrial Application, vol. 51, no. 1, pp. 336-343, Jan. 2015.

13. J.I. Itoh, H. Watanabe, K. Koiwa and Y. Ohnuma, "Experimental verification of single-phase inverter with power decoupling function using boost-up chopper," 15th European Conf. Power Electronics and Applications (EPE), Lille, 2013, pp. 1-10.

14. H. Li, K. Zhang, H. Zhao, S. Fan and J. Xiong, "Active power decoupling for high-power single-phase PWM rectifiers," IEEE Trans. Power Electronics, vol. 28, no. 3, pp. 1308-1319, March 2013.

15. S. Xu, L. Chang and R. Shao, "Evolution of single-phase power converter topologies underlining power decoupling," Chinese J. of Electrical Engineering (CJEE), vol. 2, no. 1, pp. 24-39, June 2016.

16. Manoj R. Hans, Varsha A. Patil, "Non transformer ZVZCS resonant PWM(RPWM)DC DC converter for high step up and high power applications, IEEE International Conference on Energy Systems and Applications", 2015.

17. Hans, Manoj, and Vivekkant Jogi. "Peak load scheduling in smart grid using cloud computing." Bulletin of Electrical Engineering and Informatics 8, no. 4 (2019): 1525-1530.

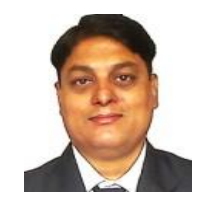

\section{AUTHORS PROFILE}

Manoj R. Hans, Having an experience of 19+ years in academics. He has graduated in 1995 from Bharati Vidyapeeth's College of Engineering, Pune and post-graduation in 2005 from PVG's College of Engineering \& Technology, Pune. Working as Associate Professor at ZCOER, Pune. He has 16 publications including International Journals and Conferences. 1

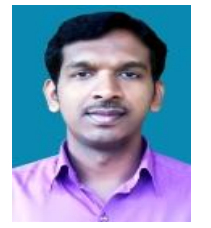

Godashe Kiran Satappa He received B.E. degree in Electrical Engineering from University of Mumbai, Maharashtra, India in 2012. He is currently working as an Assistant Professor in Rajaram Shinde college of Engineering, Chiplun, Maharashtra, India. His Research interests include dc-dc and dc-ac converters for single phase bridge inverters for photovoltaic applications.

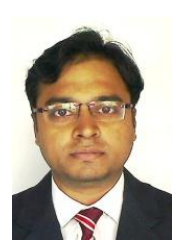

Satya Prakash, He is having an experience of 10 years in academics and done post-graduation from MANIT Bhopal in 2012. He is currently working at ZCOER, Pune as Assistant Professor. He has published 1 book chapter and 9 international conference and journal paper. His research area is power system, converters, smart grid.

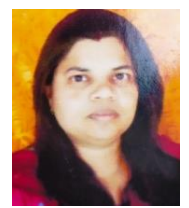

Anamika Chourasia, She has completed her graduation in Electrical Engineering in 2005. Currently working at govt. polytechnic college, Naogaon, India. She has published 3 international papers. Area of interest is power system and smart grid. 